\title{
A saída do Reino Unido da União Europeia. Um acordo tirado a ferros
}

The Exit of the United Kingdom from the European Union. A One Last Push

Agreement

La sortie du Royaume-Uni de l'Union européenne. Un accord obtenu à l'arraché

António Goucha Soares

\section{CpenEdition}

\section{Journals}

\section{Edição electrónica}

URL: https://journals.openedition.org/rccs/12390

DOI: $10.4000 /$ rccs. 12390

ISSN: 2182-7435

Editora

Centro de Estudos Sociais da Universidade de Coimbra

Edição impressa

Data de publição: 1 dezembro 2021

Paginação: 3-24

ISSN: 0254-1106

\section{Refêrencia eletrónica}

António Goucha Soares, "A saída do Reino Unido da União Europeia. Um acordo tirado a ferros»,

Revista Crítica de Ciências Sociais [Online], 126 | 2021, publicado a 27 janeiro 2022, consultado a 29 janeiro 2022. URL: http://journals.openedition.org/rccs/12390 ; DOI: https://doi.org/10.4000/rccs. 12390

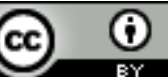




\title{
ANTÓNIO GOUCHA SOARES
}

\section{A saída do Reino Unido da União Europeia. Um acordo tirado a ferros*}

\begin{abstract}
Este artigo incide sobre a saída do Reino Unido da União Europeia (UE), em virtude do referendo sobre o Brexit, analisando a intervenção dos diferentes atores políticos envolvidos no acordo de retirada. Começa por abordar as estratégias negociais do Reino Unido e da União Europeia, para em seguida se deter sobre a tensão política entre Governo e Parlamento britânicos em torno da aprovação do acordo de saída - e a forma como a UE pautou a sua conduta ao longo dessa disputa. Refere ainda a intervenção de órgãos jurisdicionais na resolução de conflitos políticos relacionados com o Brexit. O artigo propõe uma análise crítica da atitude dos principais intervenientes no acordo, assim como uma reflexão sobre os efeitos colaterais deste processo.
\end{abstract}

Palavras-chave: Brexit; conflito político; construção europeia; política internacional.

\section{Introdução}

A saída do Reino Unido da União Europeia (UE) - o chamado Brexit constitui um revés no processo de integração europeia. Por um lado, por se tratar do primeiro país a abandonar a UE, abrindo uma fissura no bloco, e, por outro, porque o Reino Unido era um dos maiores Estados-membros: o terceiro país com mais população, sendo considerada a quinta economia mundial ao tempo da retirada da UE e a segunda a nível continental. ${ }^{1}$

Acresce que o Reino Unido é o único país europeu que mantém vestígios de potência mundial. Tem um lugar permanente no Conselho de Segurança das Nações Unidas, em virtude do seu protagonismo na Segunda Guerra Mundial (Judt, 2016: 197). É uma potência nuclear e possui as Forças

* O presente artigo decorre de um projeto de pesquisa sobre o Brexit, iniciado com o referendo sobre a saída do Reino Unido da União Europeia, continuado pelo procedimento de retirada formal e completado pelo acordo de comércio entre as partes. O resultado global desse projeto foi consolidado em Brexit: a saída do Reino Unido da União Europeia (Soares, 2021), para onde se remete para uma análise mais aprofundada desta temática.

${ }^{1}$ Consultado a 03.07.2020, em https://www.focus-economics.com/blog/the-largest-economiesin-the-world. 
Armadas dotadas de maior capacidade operacional em toda a Europa. Pela posição privilegiada na governação mundial e pelo seu poderio militar, o Reino Unido é o país europeu mais bem colocado para influenciar as questões relativas à paz e segurança internacionais. Sem o Reino Unido, a visibilidade da UE na política internacional resulta ainda mais diminuta.

A saída do Reino Unido vem transformar a própria geopolítica da UE. Com efeito, o papel crescente dos Estados-membros no processo político desta organização reforçou o protagonismo dos países grandes na construção europeia. Por seu turno, a subalternização das instituições europeias - mormente da Comissão Europeia - ao ditame dos países hegemónicos acentuou a posição dominante destes no seio da UE.

Com as suas posições contrastantes nas áreas sensíveis da UE - da moeda única ao controlo de fronteiras, passando pela defesa e pelas linhas vermelhas no processo de decisão - o Reino Unido procurou contrariar as forças centrípetas predominantes no processo de integração (Larik, 2020: 6). Para além disso, e por nunca ter pretendido assumir a liderança, o Reino Unido funcionava como contrapeso natural das potências hegemónicas. Pelo que a saída deste Estado-membro desequilibra a construção europeia porque a UE fica privada da potência com maior aptidão para contrabalançar as tentações hegemónicas latentes.

A UE encarou a saída anunciada do Reino Unido como uma ameaça existencial para o projeto de construção europeia, temendo o risco de contágio a outros Estados-membros e a sua subsequente desintegração. Por esses motivos, o acordo de saída deveria fixar condições suscetíveis de dissuadir outros países de ponderar a retirada da UE. Para alcançar esse propósito, a UE deveria agir de modo uniforme, fortalecendo a sua capacidade negocial.

Este artigo incide sobre a saída do Reino Unido da UE, na sequência do referendo de 2016 sobre o Brexit, analisando a intervenção dos atores políticos envolvidos no acordo de retirada. Começa por versar as estratégias negociais do Reino Unido e da UE, para em seguida se deter sobre a tensão política entre Governo e Parlamento britânicos em torno da aprovação do acordo de saída - e a postura da UE ao longo dessa disputa - observando ainda a intervenção de órgãos jurisdicionais chamados a resolver conflitos políticos relacionados com o Brexit. Apresentando uma perspetiva distinta da narrativa dominante sobre as negociações para a retirada do Reino Unido da UE, o artigo oferece uma análise crítica da atitude dos principais intervenientes no acordo de saída, assim como uma reflexão sobre os efeitos colaterais deste processo. 


\section{Governo britânico}

No rescaldo do referendo de 2016, a primeira-ministra Theresa May pretendia assegurar o cumprimento do voto dos cidadãos. A notificação da retirada do Reino Unido da UE - primeiro passo do processo de saída - reabriu a divisão interna exposta durante o referendo. Desde logo por ativistas pró-europeus que viam o Parlamento britânico como último ensejo para conter o Brexit, atendendo a que a maioria dos deputados havia votado pela permanência. Assim, um grupo de cidadãos demandou o Governo junto dos tribunais, para impedir a intenção de proceder à notificação de saída do Reino Unido da UE sem o consentimento do Parlamento, procurando judicializar uma decisão de natureza política.

O processo seria levado à decisão do Supremo Tribunal britânico, o qual entendeu que o Governo devia submeter a notificação de saída da UE a aprovação do Parlamento ( $\$ 114$ do acórdão). ${ }^{2}$ O Supremo Tribunal considerava o referendo como um instrumento de natureza política, desprovido de efeitos jurídicos em virtude do princípio constitucional da soberania parlamentar. Todavia, adiantava que seria difícil para o Parlamento ignorar o resultado do voto popular (§ 125). Atendendo ao resultado do referendo, o Parlamento britânico aprovaria o texto da notificação de saída, por larga maioria de votos na Câmara dos Comuns e por confortável margem na Câmara dos Lordes (Chaltiel, 2017: 129).

O procedimento parlamentar permitiu à primeira-ministra apresentar a notificação de saída do Reino Unido da UE, em março de 2017. ${ }^{3}$ Em carta enviada ao presidente do Conselho Europeu sublinhava que o Reino Unido se iria retirar da UE, mas não sairia da Europa, continuando a partilhar os valores europeus e reiterando o compromisso com os aliados continentais.

A carta anunciava a intenção de conseguir um acordo justo, visando a saída ordenada do Reino Unido. No tocante ao alcance das negociações, Theresa May propunha que o acordo de saída fosse celebrado em conjunto com a questão do relacionamento futuro do Reino Unido com a UE. Quanto à relação económica, May esclarecia que o Reino Unido não pretendia permanecer no mercado interno, ${ }^{4}$ em virtude da intransigência da UE sobre a indivisibilidade das liberdades de circulação. Com efeito, a imigração havia estado na base do mal-estar britânico que levou ao referendo, e da própria

\footnotetext{
${ }^{2}$ United Kingdom Supreme Court, Judgment $R$ (on the application of Miller and another) v. Secretary of State for Exiting the European Union (Appelant), UKSC 5, 24 January 2017. Consultado a 03.07.2020, em https://www.supremecourt.uk/cases/docs/uksc-2016-0196-judgment.pdf.

3 Cf. a carta de notificação de saída em https://assets.publishing.service.gov.uk/government/ uploads/system/uploads/attachment_data/file/604079/Prime_Ministers_letter_to_European_ Council_President_Donald_Tusk.pdf. Consultado a 03.07.2020.

${ }^{4}$ Cf. p. 4 da carta de notificação.
} 
decisão dos eleitores (Evans et al., 2018: 389-394), pelo que a primeira-ministra excluía que o futuro acordo pudesse conter a livre circulação de pessoas com a UE. May propunha um vasto acordo de comércio livre, abrangendo setores cruciais para as economias do Reino Unido e da UE, como os serviços financeiros e as indústrias de rede. ${ }^{5}$

A ideia da chefe do Governo sobre o relacionamento com a UE era respaldada por uma parceria em assuntos de segurança. Na verdade, se a UE saísse da sua ortodoxia conceptual de acordos comerciais limitados ao comércio de bens, o Reino Unido estenderia o relacionamento futuro à cooperação na área da segurança. Na medida em que o Reino Unido é a maior potência militar europeia, seria importante para a UE garantir um compromisso na área da segurança e defesa.

Sobre o acordo de saída, a prioridade consistia na salvaguarda dos direitos dos cidadãos europeus residentes no Reino Unido, bem como dos britânicos nos países da UE. A carta aludia à necessidade de estabelecer um acordo justo sobre direitos e obrigações do Reino Unido em virtude da retirada, bem como estabelecer um período transitório para que pessoas e empresas se pudessem adaptar à nova realidade de forma progressiva. Mencionava ainda o compromisso com o processo de paz na Irlanda do Norte e o desejo de evitar a reposição de uma fronteira física com a República da Irlanda em consequência do Brexit. ${ }^{6}$

\section{Eleições antecipadas}

O referendo de 2016 revelara um país fraturado em relação à saída da UE, com o Brexit a prevalecer para $52 \%$ dos cidadãos, contra $48 \%$ de eleitores defensores da permanência. A clivagem que o voto popular demonstrou parecia menos acentuada, todavia, no seio do Parlamento e da classe política britânica. De acordo com estudos disponíveis, $73 \%$ dos deputados do Parlamento britânico teriam votado pela permanência na UE. 7 Embora no seio do Partido Conservador essa tendência fosse mais atenuada, $56 \%$ dos deputados tinham votado contra a saída da UE por ocasião do referendo. ${ }^{8}$

Theresa May enfrentava um Parlamento composto por uma maioria de deputados pró-europeus, a quem teria de submeter o acordo final para a saída da UE. Por esse motivo, mas também para reforçar o próprio peso

\footnotetext{
${ }_{5}$ Cf. p. 5 da carta de notificação.

${ }^{6}$ Cf. pp. 4-5 da carta de notificação.

7 Edwards, Jim (2016), "This Is the Size of the Majority in the House of Commons against Brexit", Business Insider, 3 de novembro. Consultado a 03.07.2020, em https://www.businessinsider.com/ majority-house-of-commons-against-brexit-2016-11.

${ }^{8}$ Ver nota de rodapé anterior.
} 
político durante as negociações, decidiu convocar eleições antecipadas, em 2017. May acreditava na renovação da maioria absoluta do Partido Conservador, julgando beneficiar de um resultado dececionante da oposição, atendendo às baixas expectativas sobre o novo líder, Jeremy Corbyn.

O programa do Partido Conservador sobre o Brexit retomava os princípios enunciados na notificação de saída, prometendo cumprir a decisão tomada pelo voto popular. Quanto aos termos da futura relação com a UE, o programa afastava a participação do país não apenas no mercado único, como ainda na união aduaneira. ${ }^{9}$

O programa do Partido Trabalhista também afirmava o compromisso com o resultado do referendo. Todavia, pretendia concretizar a decisão popular através de um acordo de saída que previsse uma relação próxima da UE, com a participação no mercado único e na união aduaneira. Afirmava ainda que o acordo deveria proteger o emprego, os direitos dos trabalhadores e a defesa do ambiente, garantindo a participação ativa do Parlamento nas negociações de saída. ${ }^{10}$

O Partido Conservador obteria $42 \%$ dos votos, elegendo 317 deputados, contra $40 \%$ para o Partido Trabalhista, que elegeu 262 deputados. ${ }^{11}$ Todavia, o Partido Conservador perdeu a maioria absoluta no Parlamento, tendo de fazer um acordo com o Partido Democrático Unionista, da Irlanda do Norte, para a viabilização do Governo. Apesar do resultado do referendo ter sido confirmado de forma indireta nas eleições legislativas de 2017 - por $82 \%$ do eleitorado ter votado em partidos que prometiam concretizar o Brexit Theresa May não obteria a legitimação pretendida no plano político interno, em vista das negociações de saída.

Sem maioria absoluta nas eleições, a chefe do Governo ficava mais exposta às tensões no seio da sua bancada parlamentar sobre a questão da saída da UE, a qual se encontrava repartida entre o núcleo de intransigentes eurocéticos defensores de uma saída sem acordo (bard brexiteers), o grupo de centristas que pretendia uma saída ordenada, através de um acordo nos termos do programa do partido (soft brexiteers) e, ainda, a tendência filoeuropeia do partido, fiel à permanência na UE (remainers) (Duffy-Meunier, 2018: 771).

\footnotetext{
${ }_{9}$ Cf. o Manifesto do Partido Conservador em https://www.conservatives.com/our-plan/ conservative-party-manifesto-2019. Consultado a 03.07.2020.

${ }^{10}$ Cf. o Manifesto do Partido Trabalhista, em https://labour.org.uk/wp-content/uploads/2017/10/ labour-manifesto-2017.pdf (pp. 24-27). Consultado a 03.07.2020.

${ }_{11}$ Cf. os resultados em https://commonslibrary.parliament.uk/research-briefings/cbp-7979/. Consultado a 02.12.2021.
} 


\section{Estratégia negocial da União Europeia}

A perspetiva da saída do Reino Unido foi recebida como uma ameaça pela UE. Na verdade, o êxito da construção europeia assentou também na capacidade de as Comunidades Europeias atraírem novos Estados-membros. Esse processo, conhecido por alargamento, foi um dos pilares da chamada dinâmica de integração. No decurso do tempo, as Comunidades Europeias passaram de apenas seis países para uma união de 28 Estados-membros, tendo o próprio alargamento da UE sido iniciado pelo Reino Unido, em 1972, de par com a Irlanda e a Dinamarca.

A saída do Reino Unido da UE representava o oposto do alargamento: um Estado-membro que desiste de pertencer à União, e negoceia os termos da sua retirada. Por isso, Bruxelas receava que a saída do Reino Unido pudesse constituir o prenúncio da reversão do processo que ao longo de seis décadas tornou a integração europeia mais robusta. Se a entrada de novos Estados estava enquadrada pelo alargamento, a retirada do Reino Unido seria suscetível de representar o primeiro passo de uma tendência de desmembramento da UE.

Sendo o alargamento considerado um pilar do bloco europeu, o desmembramento potenciaria a desintegração da UE. Por estes motivos, a Comissão Europeia abordou a retirada do Reino Unido como uma contenda existencial: importava travar o risco de contágio, pelo que a estratégia negocial europeia deveria ser forte, uniforme e implacável. De modo que a dureza das condições de saída fosse por si mesma dissuasora do risco de transmissão a outros Estados-membros.

Competia à Comissão - um órgão de governo da UE, servida por dezenas de departamentos que se ocupam de diferentes áreas - assumir as negociações do acordo de saída. Todavia, a Comissão confiou a chefia das negociações com o Reino Unido a um dos seus antigos membros, Michel Barnier (Larik, 2020: 7). A condução das negociações europeias foi enquadrada por dois documentos: as orientações do Conselho Europeu ${ }^{12}$ e as diretrizes de negociação do Conselho, ${ }^{13}$ definindo as prioridades e a estratégia que a UE deveria seguir nas negociações.

A principal discordância com a notificação de saída apresentada por Theresa May relacionava-se com o alcance das negociações. Enquanto o Reino Unido pretendia que o acordo de saída e os termos da relação futura fossem negociados em conjunto, a UE exigia uma abordagem separada,

\footnotetext{
${ }^{12}$ Consultado a 03.07.2020, em https://www.consilium.europa.eu/media/21764/29-euco-art50guidelines-pt.pdf.

${ }_{13}$ Consultado a 03.07.2020, em https://www.consilium.europa.eu/media/21766/directives-forthe-negotiation-xt21016-ad01re02en17.pdf.
} 
com o acordo de saída negociado em primeiro lugar, e o relacionamento futuro discutido após consumada a retirada, enquanto país terceiro.

No tocante ao conteúdo, a UE confirmava a importância de assegurar a saída ordenada do Reino Unido, garantindo os direitos dos cidadãos afetados pelo Brexit. Mais exigentes se revelavam as questões financeiras, com a pretensão de o acordo incluir as obrigações do Reino Unido decorrentes do orçamento da UE e do Quadro Financeiro Plurianual, abrangendo a totalidade dos compromissos existentes e os custos de deslocalização de agências europeias em território britânico.

Assomava a ideia de que a saída da União Europeia implicaria custos financeiros elevados, em linha com o pretendido efeito dissuasor do acordo de retirada. Com efeito, no início das negociações a UE concebia que a conta de saída do Reino Unido poderia atingir um montante próximo dos 100 mil milhões de euros. ${ }^{14}$

Sobre a Irlanda do Norte, a UE manifestava o empenho na continuação do processo de paz, bem como o respeito dos acordos bilaterais entre Estados - com destaque para a zona de deslocação comum. As orientações afirmavam a necessidade de soluções flexíveis para evitar a criação de uma fronteira física entre os dois países, no respeito pela integridade da ordem jurídica da UE.

Para além das orientações e diretrizes mencionadas, caberá recordar que a abordagem que a UE fez das negociações de saída não divergia da postura assumida nos processos de adesão de novos países. Com efeito, para a UE a saída seria um processo simétrico da adesão. Nos processos de adesão europeia não existe negociação verdadeira, entendida como encontro da vontade das partes. A UE surge em posição de força negocial plena, apresentando uma espécie de caderno de encargos que o país candidato terá de preencher em vista da adesão. Em termos gerais, as negociações estendem-se por uma trintena de capítulos, nos quais se divide o chamado acervo comunitário, ou seja, o conjunto do direito europeu.

Desde a adesão do Reino Unido que a Comissão mantém o princípio da indivisibilidade do acervo. Daí os países candidatos terem de aceitar todas as exigências europeias. A UE concede apenas ligeiras derrogações temporárias, no âmbito dos períodos transitórios. Em contrapartida, os Estados-membros podem adiar obrigações com os recém-chegados, como a livre circulação de pessoas (Sedelmeier, 2015: 423). Deste modo,

14 Brunsden, Jim (2017), "Barnier Says UK Must Accept Principle of Brexit Bill", Financial Times, 12 de julho. Consultado a 03.07.2020, em https://www.ft.com/content/ f149365a-66f8-11e7-9a66-93fb352ba1fe. 
não se trata de uma negociação entre iguais. O encontro de vontades é feito nos moldes de um contrato de adesão, com um período de adaptação do segundo contraente.

A UE transferiu esta abordagem para as negociações de saída. Os negociadores da União elaboraram um caderno de encargos que apresentaram ao Reino Unido, impondo o seu próprio calendário. Foi assim que definiram que o acordo de saída deveria preceder o acordo sobre o relacionamento futuro, do mesmo modo que determinaram as diferentes fases em que se processariam as negociações.

Para além da lógica que protege a hegemonia negocial da UE nos processos de adesão - transposta para as negociações de saída - os 27 Estados-membros revelaram grande coesão no decurso dessas negociações. Tendo em conta a existência de clivagens profundas no Governo e Parlamento britânicos sobre o próprio Brexit, assim como nos principais partidos políticos, seria previsível que as negociações de retirada se desenrolassem em situação de desequilíbrio claro entre as partes (Jones, 2019: 33 ).

De referir que membros das instituições europeias oriundos do Reino Unido instavam à firmeza negocial da UE, aventando que um acordo de saída que fixasse condições rigorosas jamais conseguiria o aval do Parlamento britânico. Sendo certo que em Bruxelas havia ainda expectativa quanto à possibilidade de reversão do Brexit, à semelhança do ocorrido em referendos sobre a UE noutros países. Uma ilusão que atravessaria todo o período negocial.

\section{Acordo de saída}

As negociações tiveram início em 2017 e procederam de acordo com o plano fixado pela UE. No final do ano as partes chegaram a entendimento sobre as questões essenciais para a retirada do bloco europeu, adotando um relatório de progresso da primeira fase. ${ }^{15}$ Embora sublinhando que nada estaria acordado até que tudo fosse acordado, o relatório conjunto referia o compromisso sobre os direitos dos cidadãos europeus residentes no Reino Unido e dos cidadãos britânicos residentes em países da União Europeia - preocupação comum - assegurando o direito de residência permanente, e a respetiva igualdade de tratamento.

Em relação à conta de saída, era especificada a metodologia para determinar os custos financeiros imputáveis ao Reino Unido em virtude da retirada

\footnotetext{
${ }_{15}$ Consultado a 03.07.2020, em https://ec.europa.eu/info/publications/joint-report-negotiatorseuropean-union-and-united-kingdom-government-progress-during-phase-1-negotiations-underarticle-50-teu-united-kingdoms-orderly-withdrawal-european-union_en.
} 
da UE, bem como os princípios utilizados para o cálculo financeiro. Eram remetidas para a segunda fase das negociações as questões relativas à execução da metodologia e à fixação do calendário de pagamentos.

Sobre as relações entre a República da Irlanda e a Irlanda do Norte, o referido relatório reafirmava o compromisso com o processo de paz e os acordos de 1998, assim como a intenção de manter relações de cooperação Norte-Sul e evitar a reposição da fronteira física entre os dois países, considerando as circunstâncias particulares da ilha. Todavia, caso isso não fosse viável, o Reino Unido manteria o alinhamento com as regras do mercado interno e da união aduaneira, entendidas como sustentáculo da cooperação Norte-Sul e dos acordos de paz (cf. ponto 49 do relatório de progresso da primeira fase).

Face ao progresso realizado, o Conselho da UE definiu orientações para a segunda fase das negociações, relativas ao período de transição e à fixação do texto final. ${ }^{16} \mathrm{~A}$ UE definia que o período transitório expiraria no final de 2020; durante este período o Reino Unido aplicaria o acervo comunitário na íntegra, participaria no mercado único e na união aduaneira, observando a política comercial comum da UE, sem poder concluir acordos comerciais com terceiros (Larik, 2020: 25); acresce que o Reino Unido deixaria de participar nas instituições e no processo de decisão da UE durante o período de transição.

No decurso da segunda fase negocial o problema da fronteira da Irlanda cedo se revelaria o detonador das dificuldades para a aceitação do acordo no Reino Unido. A solução encontrada para evitar a reposição da fronteira física havia sido condicionada pelo relatório conjunto. Barnier pretendia que, na falta de entendimento, a Irlanda do Norte devesse permanecer no mercado interno. O Governo britânico alegava que a alternativa poderia passar por uma solução aduaneira que fizesse uso de inovações técnicas para evitar a existência de controlos. Não convencida da eficácia da solução à luz das tecnologias disponíveis, a Comissão Europeia exigia que o acordo de saída previsse uma cláusula de salvaguarda para impedir a reposição da fronteira física, o chamado backstop plan.

A cláusula de salvaguarda previa que se as partes não chegassem a acordo sobre os termos da futura relação até final do período transitório, o Reino Unido permaneceria na união aduaneira para evitar a reposição da fronteira física, sendo que a Irlanda do Norte ficaria sujeita às regras do mercado único (de Mars et al., 2018: 4).

16 Consultado a 03.07.2020, em https://www.consilium.europa.eu/media/32504/xt21004ad01re02en18.pdf. 
As apreensões provocadas pela cláusula de salvaguarda na política britânica decorriam sobretudo do horizonte de aplicação: não podendo ser revogada por via unilateral, nem contendo um prazo de aplicação, foi tida pelo Parlamento como um mecanismo ardiloso para reter o país na união aduaneira, por tempo indeterminado. Sendo certo que tal situação serviria de premissa das negociações sobre o relacionamento comercial futuro, ${ }^{17}$ ou seja, predefinindo um vínculo permanente do Reino Unido com a união aduaneira.

A versão final do acordo de saída seria alcançada no final de $2018,{ }^{18} \mathrm{em}$ linha com os relatórios intercalares. Para além da questão do backstop sobre a fronteira da Irlanda, o acordo final confirmava o compromisso sobre direitos dos cidadãos. No tocante à vertente financeira, o valor da conta de saída do Reino Unido seria determinado através da metodologia e dos princípios para fixação do cálculo dos encargos de retirada. De acordo com o Governo britânico, a estimativa de encargos financeiros globais com a saída da UE ficaria entre 40 a 45 mil milhões de euros ( 35 a 39 mil milhões de libras esterlinas), ${ }^{19}$ verba inferior às pretensões iniciais da Comissão.

A aprovação do acordo de saída em Conselho de Ministros provocaria cisão no Governo britânico, com a demissão dos membros da ala eurocética. O secretário de Estado para o Brexit, Dominic Raab, afirmava que as negociações tinham produzido um acordo aceitável, com exceção da cláusula de salvaguarda, resultado de intolerável pressão. Raab considerava que os termos do backstop conferiam à UE um veto sobre a manutenção do Reino Unido na união aduaneira que se poderia prolongar por tempo indefinido, sendo necessário proceder à sua renegociação.

A contestação sobre o backstop seria acrescentada pelo parecer de Geoffrey Cox, Attorney General, sobre o acordo de saída, afirmando que a cláusula de salvaguarda, por não permitir a desvinculação unilateral do Reino Unido, nem prever um prazo limite para a sua aplicação, poderia servir de expediente para amarrar o país numa união aduaneira com a UE. ${ }^{20}$

\footnotetext{
${ }_{17}$ McTague, Tom; Barigazzi, Jacopo; Vela, Jakob Hanke (2018), "Brussels Seeks Permanent Post-Brexit Customs Union”, Politico, 13 de novembro. Consultado a 03.07.2020, em https://www. politico.eu/article/brussels-wants-permanent-post-brexit-customs-union/.

${ }_{18}$ Jornal Oficial da União Europeia, 2019/C 66 I, 19 de fevereiro de 2019. Consultado a 03.07.2020, em https://eur-lex.europa.eu/legal-content/PT/TXT/PDF/?uri=OJ:C:2019:066I:FULL\&from=EN. ${ }_{19}$ Cf. p. 30 do documento consultado a 03.07.2020, em https://assets.publishing.service.gov.uk/ government/uploads/system/uploads/attachment_data/file/759020/14_November_Explainer_for_ the_agreement_on_the_withdrawal_of_the_United_Kingdom_of_Great_Britain_and_Northern_ Ireland_from_the_European_Union.pdf.

${ }^{20}$ Cf. o debate na Câmara dos Comuns do Parlamento britânico, a 3 de dezembro de 2018, consultado a 03.07.2020, em https://hansard.parliament.uk/commons/2018-12-03/debates/ 67B4BC40-0578-417D-9467-F737BDD5079C/WithdrawalAgreementLegalPosition.
} 
A intervenção do Attorney General teve o condão de acicatar os deputados, pelo que o acordo de saída parecia condenado à rejeição no Parlamento, caso não fosse alterada a disposição sobre o backstop. Com efeito, o Parlamento não parecia disponível para transigir com uma cláusula que remeteria o país para um longo purgatório.

\section{Parlamento britânico}

O acordo para a retirada da UE deveria ser ratificado pelo Parlamento britânico. Em caso de recusa, o Reino Unido abandonaria o bloco europeu no final de março de 2019, dois anos após a notificação de saída, salvo se os Estados-membros acordassem na prorrogação do prazo. Assim, a opção que se colocava aos deputados seria entre a saída nos termos do acordo com a UE, ou a saída sem acordo, que se produziria por defeito.

Todavia, os defensores mais intransigentes da permanência na UE não haviam deixado de procurar contrariar o desenlace anunciado. Assim, membros dos Parlamentos britânico, europeu e escocês interpuseram um pedido judicial, questionando se a notificação de saída do Reino Unido poderia ser revogável e, em caso afirmativo, se o país mantinha o estatuto de membro da UE. Pretendiam que o pedido fosse remetido ao Tribunal de Justiça da União Europeia (TJUE), para que este se pronunciasse sobre a revogabilidade da notificação de saída, como viria a suceder.

A Comissão Europeia tentou evitar a decisão do Tribunal europeu, apontando a natureza hipotética da questão colocada. Contudo, o Tribunal de Justiça observou que um dos autores do pedido pertencia ao Parlamento britânico, a quem competia o voto sobre o acordo de saída, pelo que teria interesse na pergunta suscitada, a qual poderia alargar o leque de opções disponíveis.

Para o TJUE, o artigo $50^{\circ}$ do Tratado da União Europeia prevê o direito soberano de um Estado-membro abandonar a UE ( $\$ 56$ do acórdão). ${ }^{21}$ Ainda que não refira a revogação da notificação de saída, o TJUE afirmou que ela reflete a decisão soberana do Estado preservar o estatuto de membro da UE, não sendo prejudicada pela notificação de saída (§ 59). Enquanto prerrogativa decorrente da soberania, a revogação da notificação de saída não dependeria da anuência dos Estados-membros, como pretendiam o Conselho e a Comissão (Armstrong, 2019: 37).

Assim, o TJUE declarou a revogabilidade da notificação de saída, até ao derradeiro momento de participação na UE. Ao alargar o leque de escolhas

${ }^{21}$ Acórdão do Tribunal de Justiça, Andy Wightman e outros contra Secretary of State for Exiting the European Union, processo C-621/18, 10 de dezembro de 2018. Consultado a 03.07.2020, em https://eur-lex.europa.eu/legal-content/PT/TXT/PDF/?uri=CELEX:62018CJ0621\&from=pt. 
dos membros do Parlamento britânico (Koutrakos, 2019: 1), o TJUE entrava de forma involuntária no terreno da disputa política sobre a saída do Reino Unido da UE. Apesar da consistência da argumentação jurídica, o TJUE proferiu um acórdão de questionável oportunidade política, por permitir a instrumentalização jurisdicional de uma matéria com clara natureza política (Gomes, 2018: 238).

No âmbito da UE, o acordo de saída seria aprovado a 25 de novembro de 2018 pelo Conselho Europeu. Esta decisão seria confirmada no mês seguinte nas conclusões de uma reunião extraordinária na qual o Conselho esclareceu - perante as dificuldades sentidas por May na questão do backsktop, solicitando uma clarificação sobre o seu alcance - "que a solução de último recurso foi concebida como uma apólice de seguro para evitar uma fronteira física na ilha da Irlanda e assegurar a integridade do mercado único", afirmando que "o acordo não estava aberto à renegociação". ${ }^{22}$ No Reino Unido, por seu turno, a inclusão da cláusula de salvaguarda no acordo de saída serviu de pretexto para uma rebelião no Partido Conservador, culminando com a apresentação de uma moção de censura à liderança de Theresa May, que seria no entanto recusada.

A primeira-ministra adiaria para 2019 a votação do acordo de saída pelo Parlamento, receando o voto de rejeição por parte dos conservadores eurocéticos e dos unionistas irlandeses, junto com o da oposição (Heinkelmann-Wild et al., 2020: 732). O adiamento da votação não impediria May de sofrer uma pesada derrota, com o acordo de saída a ser recusado por 432 deputados, por uma diferença de 230 votos.

A chefe do Governo tentaria em seguida obter concessões da UE sobre a cláusula de salvaguarda, que permitissem a aprovação do acordo de saída pelo Parlamento britânico. Em resposta, os dirigentes europeus reafirmaram que havia apenas um acordo de saída, cujas negociações haviam sido concluídas, pelo que o seu conteúdo não poderia ser reaberto. O Governo agendaria então outra votação do acordo, antes do prazo fixado para a saída da UE. Todavia, no mês de março o Parlamento recusaria de novo a ratificação do acordo de saída, por um diferencial de 149 deputados. Os esforços de May permitiram ainda assim conquistar dezenas de votos entre os membros da sua bancada, reduzindo o número de parlamentares rebeldes.

Face à situação gerada pela recusa de ratificação, o Parlamento foi chamado a manifestar preferência sobre cenários alternativos ao acordo de

${ }^{22}$ Cf. p. 2 das conclusões da reunião em https://data.consilium.europa.eu/doc/document/ XT-20022-2018-INIT/pt/pdf. Consultado a 03.07.2020. 
Theresa May, através de votos indicativos que pudessem abrir caminho a nova estratégia. Os cenários propostos iam da revogação da saída ao abandono da UE sem acordo; da realização de um referendo confirmativo sobre o acordo de saída à manutenção do Reino Unido na união aduaneira; do reingresso na Associação Europeia de Comércio Livre (EFTA, na sigla em inglês) - com a permanência no mercado interno - à celebração de um acordo de comércio livre com a UE. Porém, todas as alternativas propostas seriam recusadas pelo Parlamento, agravando o impasse criado sobre a saída da UE.

May faria ainda uso de um subterfúgio, para ladear obstáculos que impediam a votação de uma proposta recusada por duas vezes: apresentaria apenas o acordo de saída à apreciação dos deputados, separado da declaração política sobre a futura relação com a UE. Tal não impediria, contudo, que o Parlamento chumbasse pela terceira vez o acordo negociado pelo Governo, por uma diferença de 58 votos. May conseguiria o voto favorável de parte da ala eurocética - entre os quais Boris Johnson e Dominic Raab - ao contrário do sucedido nos sufrágios precedentes.

A reiterada rejeição do acordo de saída, bem como a recusa sistemática de cenários alternativos submetidos a voto indicativo da Câmara dos Comuns, mostravam a dificuldade do Parlamento britânico em lidar com a retirada da UE (Stockemer, 2019: 116). Mesmo que a maioria dos seus membros entendesse que a decisão sobre a saída, em virtude da sua complexidade técnico-política, devesse ter sido tomada apenas no recato da instituição representativa, certo é que o imbróglio político gerado pelo comportamento dos deputados não iluminava as vantagens comparativas da decisão pelo Parlamento.

Inabalável, Theresa May empreenderia uma derradeira tentativa para aprovar o acordo, buscando apoio no Partido Trabalhista. Atendendo às pretensões deste sobre o relacionamento futuro com a UE - a união aduaneira - e a vontade da maioria dos seus deputados submeter o acordo de saída a nova consulta popular, o Governo aprovaria um esboço de entendimento com a oposição. Além da resposta gélida do Partido Trabalhista, o plano desencadearia a fúria dos eurocéticos, os quais consideram a hipótese de um novo referendo como uma traição. Devastada pela avalanche de protesto no seu Partido, ampliada pela recusa dos trabalhistas e a crítica dos unionistas irlandeses, May apresentaria o pedido de renúncia em maio de 2019.

\section{Governo Boris Johnson}

A rejeição sucessiva do acordo concluído pelo Governo de Theresa May implicou o adiamento da saída da UE. Situação que colocava o Reino 
Unido na obrigação de participar nas eleições europeias de 2019, pois não tendo concretizado a retirada, o país permanecia membro do bloco europeu. As eleições para o Parlamento Europeu coincidiam com a turbulência na política britânica, marcada por clivagens profundas em redor do Brexit. Perante a incapacidade do Parlamento britânico em alcançar consenso para a aprovação do acordo de saída, Nigel Farage - antigo líder do Partido de Independência do Reino Unido e conhecido deputado europeu - espreitou a oportunidade para repetir o protagonismo nas eleições europeias.

Aproveitando um novo partido - o Partido do Brexit - que reclamava a retirada imediata do Reino Unido da UE, o discurso populista permitiu atrair o voto de protesto dos eleitores exasperados com o folhetim da saída (Mény, 2020: 163). Este partido alcançaria assim a vitória nas eleições europeias, com $30,7 \%$ dos votos e 29 deputados eleitos, em contraste com o Partido Conservador reduzido a $8,8 \%$ dos votos, elegendo apenas quatro deputados, sendo que por seu turno, o Partido Trabalhista cairia para terceiro lugar, com $13,7 \%$ dos votos, elegendo dez deputados. ${ }^{23}$

Os resultados das eleições europeias serviram de barómetro do comportamento dos cidadãos: o Partido do Brexit conseguira esvaziar o voto no Partido Conservador, remetido para um humilhante quinto lugar (Heinkelmann-Wild et al., 2020: 735). Pelo que o eleitorado conservador manifestara clara preferência pela saída da UE, ao arrepio da atitude errática dos representantes parlamentares. Em resultado, a sangria de votos no Partido Conservador nas eleições europeias contribuiria para radicalizar o posicionamento estratégico da futura liderança, no tocante à retirada da UE.

A escolha do sucessor de Theresa May na chefia do Governo seria realizada de forma nova. $\mathrm{O}$ novo primeiro-ministro resultaria não apenas da escolha dos membros da sua bancada parlamentar (Levistsky e Ziblatt, 2018: 115), mas precisava do voto complementar dos militantes do Partido, entre os candidatos mais votados pelos deputados. Numa primeira fase, os deputados fariam sufrágios sucessivos; a seguir, os militantes do Partido Conservador elegeriam o novo líder partidário e, por inerência, o primeiro-ministro britânico.

Nos sufrágios dos deputados, Boris Johnson emergiu como preferido entre os contendentes eurocéticos, com o voto da maioria do grupo parlamentar, o qual via nele o candidato melhor colocado para estancar a

${ }_{23}$ Consultado a 03.07.2020, em https://election-results.eu/national-results/united-kingdom/ 2019-2024/. 
sangria eleitoral sofrida pelo Partido. Por seu turno, Jeremy Hunt seria o candidato com apoio da ala moderada. Na votação junto da base do Partido Conservador, Boris Johnson obteria o dobro das escolhas do adversário, conseguindo a preferência de dois terços do partido.

Será interessante recordar que, por ocasião da eleição de Theresa May para a liderança do Partido Conservador, Boris Johnson foi afastado pelos seus pares nas primeiras votações, por alegada falta de perfil para o exercício do cargo de primeiro-ministro. Porém, três anos volvidos conseguiria apoio expressivo da bancada parlamentar para o desempenho do mesmo cargo, bem como dos militantes do partido. A inflexibilidade da UE face aos reiterados pedidos de May para renegociar o mecanismo de salvaguarda da fronteira da Irlanda do Norte terá pesado na mudança de perceção sobre o perfil requerido para chefe do Governo britânico.

Boris Johnson não demoraria a exibir credenciais de líder forte, ao estilo das chamadas democracias iliberais (Mény, 2020: 143). Tendo começado por afastar do partido os deputados que não haviam acatado a disciplina de voto sobre a lei que obstava à saída da UE sem acordo, em seguida, e recorrendo a um expediente constitucional, decretaria a suspensão do Parlamento até meados de outubro. Tendo em conta que a extensão do prazo de saída concedido pela UE expirava no final desse mês, a interrupção dos trabalhos parlamentares tornaria plausível uma retirada da UE sem acordo, frustrando a intervenção da Câmara dos Comuns.

A decisão de suspender o Parlamento foi percebida como um golpe constitucional, não apenas pela oposição, mas também por deputados conservadores que defendiam a saída ordenada da UE. À semelhança do sucedido com Theresa May, no tocante à notificação da retirada, o diferendo seria decidido pelo poder judicial. No entender de alguns tribunais do Reino Unido a suspensão do Parlamento revestia apenas natureza política, não devendo ser resolvida por via judicial. Contudo, o Supremo Tribunal do Reino Unido reclamaria a competência para deliberar sobre o assunto, na medida em que teria de indagar sobre a existência de limites para o exercício da prerrogativa constitucional invocada pelo primeiro-ministro.

Para o Supremo Tribunal, a suspensão prolongada decretada por Boris Johnson atentava contra a essência da soberania parlamentar, bem como contra o princípio constitucional da responsabilidade do Governo perante o Parlamento - na medida em que impedia este último da fiscalização do executivo e do exercício da função legislativa. Tendo os motivos para a suspensão parlamentar sido rejeitados com base em evidências do julgamento, 
o Supremo Tribunal declarou a nulidade da decisão contestada, afirmando que o primeiro-ministro havia abusado dos seus poderes. ${ }^{24}$

\section{Novo acordo de saída}

Se o estilo de liderança de Boris Johnson não deveria ser motivo de surpresa, a atitude da UE em relação ao impasse sobre o acordo de saída revelaria um volte-face imprevisto, com o presidente da Comissão, Jean-Claude Juncker, a aceitar discutir a questão da fronteira irlandesa, caso o Reino Unido apresentasse uma alternativa viável.

Como pano de fundo existia um relatório sobre Alternative Arrangements à cláusula de salvaguarda, elaborado por um grupo de deputados a pedido do Parlamento britânico. ${ }^{25} \mathrm{O}$ extenso documento fazia um estudo comparativo de diferentes ligações fronteiriças com relações económicas especiais, bem como o regime aplicável em regiões insulares, visando identificar mecanismos testados que pudessem servir de auxílio para a questão da fronteira da Irlanda do Norte. A análise da situação nas fronteiras da Noruega com a Suécia, da Suíça com países da UE, do Canadá com os Estados Unidos, ou da Austrália com a Nova Zelândia, demonstrava um conjunto de procedimentos que permitiriam efetuar controlos no comércio Norte-Sul de mercadorias, não acarretando o retorno da fronteira física entre as duas Irlandas.

O fundamento da UE para defender a natureza inegociável do mecanismo de salvaguarda do acordo de saída - porque só ele permitia evitar a reposição da fronteira física na Irlanda do Norte, preservando a integridade do mercado interno - seria contrariado pela variedade de soluções reveladas no citado relatório. Situação que terá contribuído para aplacar a intransigência europeia em relação ao backstop.

O efeito combinado do relatório sobre alternativas ao mecanismo de salvaguarda e do estilo veemente do primeiro-ministro britânico acabaria por beneficiar a conclusão de um novo acordo de saída da UE, em breve tempo. Replicando em larga medida o acordo concluído por Theresa May sobretudo em matéria de direitos dos cidadãos, em relação à conta de saída a cargo do Reino Unido e aos termos do período de transição - o acordo obtido por Boris Johnson envolveria algumas cedências da parte da UE.

Desde logo, a reabertura do texto do acordo anterior - que a UE declinou de forma reiterada, apesar dos insistentes pedidos da primeira-ministra May-

\footnotetext{
${ }^{24}$ United Kingdom Supreme Court, $R$ (on the application of Miller) (Appellant) $v$ The Prime Minister (Respondent), UKSC 41, 24 September 2019. Consultado a 03.07.2020, em https://www. supremecourt.uk/cases/uksc-2019-0192.html.

${ }_{25}$ Ver "Alternative Arrangements for the Irish Border", em http://uniserve.co.uk/wp-content/ uploads/2019/10/Alternative-Arrangements-for-the-Irish-Border.pdf. Consultado a 03.07.2020.
} 
com a revisão do sacrossanto protocolo sobre a fronteira da Irlanda do Norte. Com efeito, a Irlanda do Norte ficaria sujeita a um regime aduaneiro misto: integraria o sistema tarifário do Reino Unido, mas obedeceria à regulação técnica aplicável aos produtos do bloco europeu (Larik, 2020: 28). Pelo que o acordo de Boris Johnson previa a realização de controlos fronteiriços no mar da Irlanda.

Em resultado, incumbe às autoridades do Reino Unido executar os procedimentos alfandegários sobre produtos britânicos destinados à República da Irlanda, bem como realizar controlos veterinários no trânsito de animais. Deste modo, o controlo sobre a entrada de bens na união aduaneira é efetuado por um país terceiro, ao arrepio da preocupação com a integridade do mercado interno que, no entender de Barnier, implicava a existência de rigorosas fiscalizações nas fronteiras externas do bloco europeu.

Para além do Reino Unido ter conseguido readquirir o poder de realizar acordos comerciais com outros países, o novo acordo de saída atribui à Irlanda do Norte a faculdade de se eximir do regime aduaneiro misto no final do primeiro quadriénio, por deliberação da sua Assembleia.

Por sua vez, a Declaração Política sobre o relacionamento futuro prevê apenas a realização de um acordo de comércio livre com a UE, limitando a ambição do compromisso previsto por Theresa May. Acresce que a exigência da UE quanto aos níveis de proteção assegurados no futuro acordo - o chamado level playing field - deixou de constar do articulado do acordo de saída, sendo apenas objeto de referência no texto da Declaração Política, sem caráter vinculativo.

Apesar do novo acordo de saída ter sido depurado dos assuntos que provocaram os votos de repúdio do acordo de Theresa May, o Parlamento britânico suscitaria novos obstáculos para a sua ratificação, protelando o abandono da UE. A incapacidade de o Parlamento aquiescer na retirada da UE determinaria a realização de eleições antecipadas para a Câmara dos Comuns, no final de 2019. Os Conservadores alcançariam uma vitória esmagadora, mercê de uma campanha focada na concretização do Brexit, em contraste com a estratégia equívoca do Partido Trabalhista, elegendo mais 160 deputados que o seu antagonista. Em resultado, o Parlamento exibiria uma maioria de membros sintonizada com o referendo de 2016, ratificando o acordo de saída. Em janeiro de 2020, o Reino Unido abandonava a UE.

\section{Conclusão}

O procedimento de saída do Reino Unido da UE mostrou situações de grande interesse sobre o modo de funcionamento das democracias contemporâneas, bem como os riscos que enfrentam. Desde logo, a tensão 
existente entre as instituições representativas e os mecanismos de democracia direta. Seria necessário recorrer por duas vezes a eleições antecipadas para o Parlamento britânico alcançar uma maioria de membros que aceitasse a retirada da UE, deliberada pelo voto dos cidadãos, alvitrando a crise do sistema de representação.

$\mathrm{Na}$ verdade, a primeira-ministra britânica começou por dissolver o Parlamento por os seus membros terem votado a favor da permanência aquando do referendo, em larga maioria. Não obstante, o acordo para a saída da UE negociado pelo Governo de Theresa May seria rejeitado em três diferentes votações pelo novo Parlamento. Acresce que o mesmo Parlamento obstaculizaria ainda a ratificação de um acordo de saída reformulado, concluído por Boris Johnson, situação que determinaria novas eleições antecipadas.

Para além das clivagens existentes no Parlamento e nos partidos políticos sobre a questão europeia, o sistema político britânico foi atravessado por uma longa disputa político-constitucional entre, por um lado, o órgão executivo que reclamava o cumprimento de uma decisão tomada em referendo pelos cidadãos e, por outro, uma sucessão de votos e procedimentos dilatórios por parte do Parlamento que entravaram a concretização do voto popular.

A luta entre os principais atores políticos britânicos seria intermediada pelos órgãos jurisdicionais, em diversos momentos. Tanto o Supremo Tribunal do Reino Unido, como o próprio TJUE, seriam chamados a intervir no fervor da disputa política entre Governo e Parlamento, para decidir questões relacionadas com a retirada da UE. Pelo que o procedimento de saída proporcionou a oportunidade para a judicialização do conflito político entre os poderes executivo e legislativo.

Pela sua parte, a UE abordou a retirada do Reino Unido com grande cuidado. Temendo defrontar uma ameaça existencial ao projeto europeu, a União instou os Estados-membros a seguirem uma estratégia uniforme no decurso do processo negocial, por forma a conquistar uma posição de força no confronto com o Reino Unido. Em consequência, a UE conseguiria impor o conjunto das suas exigências ao Governo de Theresa May, alimentando a ideia de que a dureza negocial seria o melhor antídoto para estancar o perigo de desintegração suscitado pela retirada do Reino Unido. A coesão entre todos os Estados-membros permitiu também à UE liderar o decurso das negociações para a saída do Reino Unido, tendo alcançado um acordo final favorável às suas pretensões.

No entanto, a inflexibilidade para aceder aos apelos da primeira-ministra May para alteração do acordo evidenciou a sobranceria que a UE infundiu ao procedimento para a saída do Reino Unido. Atitude que seria também sinal de uma veleidade originada no seio das instituições europeias, logradas 
pela pressão de britânicos filoeuropeus, afiançando que um acordo de saída com condições severas para o Reino Unido jamais obteria o apoio do Parlamento britânico.

A ilusão que a rigidez europeia poderia favorecer a reversão do Brexit mostrou ter sido uma estratégia imprudente para os interesses da UE. Com efeito, não impediu a decisão do referendo de prosseguir o seu curso e favoreceu ainda a eleição de um radical eurocético para novo líder do Partido Conservador, a quem coube a chefia do Governo britânico que iria negociar o acordo comercial com a UE. Sendo certo que a rispidez do primeiro-ministro Boris Johnson - ao arrepio da tradição liberal do sistema político britânico - acabaria por incitar a UE a consentir na revisão do acordo de saída ${ }^{26}$ eliminando o polémico mecanismo de backstop relativo à fronteira da Irlanda do Norte.

Revisto por Ana Sofia Veloso

\section{Referências bibliográficas}

Armstrong, Kenneth (2019), “The Right to Revoke an EU Withdrawal Notification: Putting the Bullet Back in the Article 50 Chamber?", The Cambridge Law Journal, 78(1), 34-38.

Chaltiel, Florence (2017), "Le Brexit, la souveraineté du people et le parlementarisme britannique”, Revue de l'Union Européenne, 606, 129-130.

de Mars, Sylvia; Murray, Colin; O’Donoghue, Aoife; Warwick, Ben (2018), “The Protocol on Ireland/Northern Ireland (EU-UK Draft Withdrawal Agreement)”. Consultado a 28.05.2020, em https://ssrn.com/abstract=3287729.

Duffy-Meunier, Aurélie (2018), "Refléxions de nature constitutionnelle sur la loi sur le retrait du Royaume-Uni de l'Union Européenne, L'European Union (Withdrawal) Act 2018", Revue trimestrielle de droit européen, 4, 759-781.

Evans, Geoffrey; Carl, Noah; Dennison, James (2018), "Brexit: The Causes and Consequences of the UK's Decision to Leave the EU”, in Manuel Castells et al. (orgs.), Europe's Crises. Cambridge: Polity Press, 380-404.

Gomes, Conceição (2018), "A formação de magistrados como instrumento de transformação da justiça”, Revista Crítica de Ciências Sociais, número especial, 237-260. DOI: https://doi.org/10.4000/rccs.7881

${ }_{26}$ Cf. Menon, Anand (2019), "An Inflexible Brussels Is Damaging Its Own Interests over Brexit", Financial Times, 19 de novembro. Consultado a 03.07.2020, em https://www.ft.com/ content/69edfca4-0633-11ea-a958-5e9b7282cbd1/. 
Heinkelmann-Wild, Tim; Kriegmair, Lisa; Rittberger, Berthold; Zangl, Bernhard (2020), "Divided They Fail: The Politics of Wedge Issues and Brexit", Journal of European Public Policy, 27(5), 723-741.

Jones, Emily (2019), “The Negotiations: Hampered by the UK's Weak Strategy”, European Journal of Legal Studies, 23, 23-58.

Judt, Tony (2016), Pós-guerra. História da Europa desde 1945. Lisboa: Edições 70. Tradução de Victor Silva, Maria Manuel Cardoso da Silva e Patrícia Xavier.

Koutrakos, Panos (2019), "The European Court of Justice and the Politics of Brexit", European Law Review, 44(1), 1-2.

Larik, Joris (2020), "Brexit, the Withdrawal Agreement, and Global Treaty (Re)Negotiations”, American Journal of International Law, 114(3), 1-33.

Levitsky, Steven; Ziblatt, Daniel (2018), Como morrem as democracias. Lisboa: Vogais. Tradução de Jorge Mourinha.

Mény, Yves (2020), Democracias imperfeitas. Frustrações populares e vagas populistas. Lisboa: Imprensa de Ciências Sociais. Tradução de Pedro Cerejo.

Sedelmeier, Ulrich (2015), "Enlargement: Constituent Policy and Tool for External Governance”, in Hellen Wallace; Mark Pollack; Alasdair Young (orgs.), Policy-Making in the European Union. Oxford: Oxford University Press, 407-435 [7. a ed.]. Soares, António Goucha (2021), Brexit: a saída do Reino Unido da União Europeia. Coimbra: Actual Editora.

Stockemer, Daniel (2019), “The Brexit Negotiations: If Anywhere, Where Are We Heading? 'It Is Complicated'”, European Political Science, 18, 112-116.

\section{António Goucha Soares}

Instituto Superior de Economia e Gestão, Universidade de Lisboa | Gabinete de História Económica e Social / CSG - Investigação em Ciências Sociais e Gestão

Rua do Quelhas, n. ${ }^{\circ}$ 6, 1200-781 Lisboa, Portugal

Contacto: agsoares@iseg.ulisboa.pt

ORCID: https://orcid.org/0000-0002-4312-1406

Artigo recebido a 10.07.2020

Aprovado para publicação a 22.10.2021

https://doi.org/10.4000/rccs. 12390 
The Exit of the United Kingdom from the European Union. A One Last Push Agreement

The article examines the withdrawal agreement between the UK and the EU following the Brexit referendum including an analysis of the role of the main political actors. Beginning with the negotiation strategies of both the UK and the EU, it then concentrates on the political tensions between the British Government and Parliament with respect to the latter's approval of the agreement - as well as EU behavior throughout that dispute. The article also focuses on how courts were asked to settle disputes between the main branches of power on the issue of Brexit and proposes a critical view on the role of the stakeholders of the agreement, as well as a reflection on the collateral effects of this process.

Keywords: Brexit; European construction; international policy; political conflict.
La sortie du Royaume-Uni de l'Union européenne. Un accord obtenu à l'arraché

Cet article aborde le départ du Royaume-Uni de l'Union européenne (UE), en raison du référendum sur le Brexit, en analysant l'intervention des différents acteurs politiques impliqués dans l'accord de retrait. On commence par aborder les stratégies de négociation du Royaume-Uni et de l'UE et par la suite on s'attarde sur la tension politique entre le Gouvernement et le Parlement britanniques au sujet de l'approbation de l'accord de sortie - et sur la manière dont l'UE a guidé sa conduite tout au long de ce différend. On fait également référence à l'intervention des organes juridictionnels dans la résolution des conflits politiques liés au Brexit. On propose une analyse critique de l'attitude des principaux acteurs impliqués dans l'accord, ainsi qu'une réflexion sur les effets secondaires de ce processus. Mots-clés: Brexit; conflit politique; construction européenne; politique international. 
